\title{
ما هي المساحة التي يحتاجها البشر جميعاً للوقوف في نفس المكان واللحظة؟
}

What would be the area all humans would need to stand side-by-side in one place?

خالد مصطفى Khaled Moustafa Editor of Arabic Science Archive محرر الأرشيف العبي العلمي Email: khaled.moustafa@arabixiv.org البريد الإلكتروني

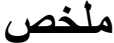

يُقدّر عدد البشر الكلي حالياً، أحياءً وأمواتاً، منذ أن وجدوا على سطح الأرض حتى الآن، بحوالي 100 مليار

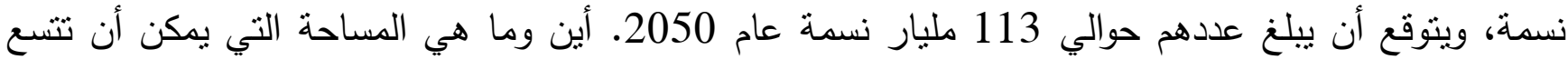
لهؤلاء جميعاً أو حشرهم (جمعهم) في نفس المكان واللحظة؟ سؤال قد يتبادر إلى أذهان الكثيرين، حول مكان وكيفية جمع الناس في مكان واحد، وأي منطقة أو مساحة يمكن أن تتسع لهم جميعاً. يمكن الإجابة عن هذأ السوأ السؤال

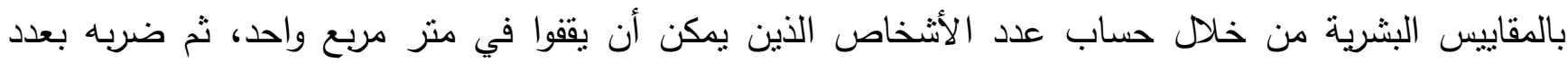
السكان الكلي. فإذا ما وقف شخص واحد إلى أربعة أشخاص في المنز المربع الواحد، فإن مساحة صغيرة نسبياً، منل مساحة بلغاريا أو كوبا أو كرواتيا أو جيبوتي أو منطقة مكة المكرمة لوحدها، في شبه الجزيرة العربية، أو ربع مساحة سوريا تكفي ونيف لوقوف جميع البشر ، جنباً إلى جنب، منذ أن وجدوا على سطح الأرض إلى عقودٍ قادمة. كلمات مفتاحية: عدد سكان الأرض، التزايد السكاني، نهاية العالم، المساحة اللازمة لوقوف جميع البشر في مكان واحد، وقوف الناس في مكان واحد، جميع البشر على سطح الأرض، سكان العالم الكلي، عدد البشر الكلي.

يتزايد عدد سكان الأرض بنسب متفاوتة، تبعاً للبلد والظروف الاقتصادية والاجتماعية والقناعات الثخصية للأفراد

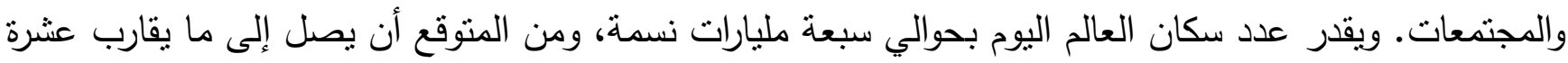
مليارات نسمة عام 2050. وتتربع الصين بسكانها البالغ عددهم أكثر من مليار وربع المليار نسمة على رأس قائمة الدول الأكثر سكاناً، تليها الهند بعدد مشابه تقريباً، ثم الولايات المتحدة بحوالي 320 مليون نسمة، فإندونيسيا بحوالي 260 مليون نسمة، ثم البرازيل وباكستان بحوالي 200 مليون نسمة لكل منهما. وتختلف الكثافة السكانية من بلد إلى آخر . فهناك بلدان ذات كثافة سكانية عالية بالنسبة إلى مساحتها (مثل سنغافورة)، وأخرى ذات كثافة سكانية قليلة في وحدة المساحة (مثل منغوليا، وأستراليا، وروسيا، والجزائر ، إلخ). 
Arabic Science Archive (arabixiv.org) 2018

أما عدد البشر الكلي -أحياءً وأمواتاً- منذ أن وجدوا على سطح الأرض حتى الآن، فيتفاوت أيضاً تبعاً للحقبة

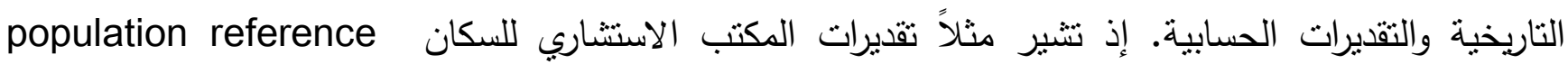
bureau 2050 (جدول 1). ويُقِّر عدد البشر الأحياء حالياً بحوالي 7 مليار نسمة، أي أقل من سبعة بالمئة (6.9 بالمئة) من إجمالي عدد البشر الكلي منذ أن وجدوا على سطح الأرض حتى يومنا هذا، وستبلغ ما يقارب 9 بالمئة بحلول عام 2050 (جدول 1).

\begin{tabular}{|c|c|c|c|}
\hline نسبة عدد السكان في السنة المشار إليها & عدد المواليد الكلي تراكمياً (أحياءً وأمواتاً) & السنة المشار إليها & (تقويم ميلادي) \\
\hline 0,6 & $47,163,122,125$ & $300,000,000$ & 1 \\
\hline 0,6 & $73,754,465,125$ & $450,000,000$ & 1200 \\
\hline 0,6 & $86,536,467,578$ & $500,000,000$ & 1650 \\
\hline 0,9 & $89,708,399,091$ & $795,000,000$ & 1750 \\
\hline 1,3 & $93,754,639,100$ & $1,265,000,000$ & 1850 \\
\hline 1,7 & $96,654,876,956$ & $1,656,000,000$ & 1900 \\
\hline 2,5 & $100,045,075,171$ & $2,516,000,000$ & 1950 \\
\hline 5,5 & $105,472,380,171$ & $5,760,000,000$ & 1995 \\
\hline 6,5 & $107,602,707,793$ & $6,987,000,000$ & 2011 \\
\hline 6,9 & $108,470,690,115$ & $7,536,000,000$ & 2017 \\
\hline 7,8 & $110,277,285,221$ & $8,563,000,000$ & 2030 \\
\hline 8,7 & $113,110,815,203$ & $9,846,000,000$ & 2050 \\
\hline
\end{tabular}

المصدر: https://www.prb.org/howmanypeoplehaveeverlivedonearth (25 حزيران 2018)

والسؤال الذي يمكن طرحه هنا: ما هي المساحة التي يمكن أن تتسع للبشر جميعاً إذا ما أزفت ساعة الحشر للوقوف بين يدي خالقهم يوم الحساب؟ بغض النظر عن قدرة البارئ عز وجل على جمع الناس بالكيفية والهيئة التي لئي

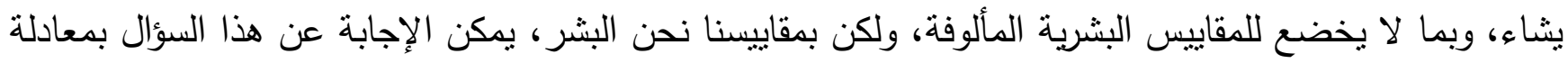
بسيطة من خلال معرفة عدد السكان الكلي ثم ضربه بمنوسط المساحة التي يشغلها الإنسان راجِاً (واقفاً على لإنى رجليه)، كالآتي:

المساحة اللازمة لوقوف جميع البشر جنباً إلى جنب في نفس المكان واللحظة = عدد البشر الكلي منذ أن وجدوا على سطح الأرض x متوسط المساحة التي يشغلها الفرد وإقفاً 
فإذا افترضنا جدلاً أن نهاية العالم ستكون بحلول عام 2050 (مجرد افتراض لا أكثر ، لا نبوءة ولا كَهَانة!)، وأن

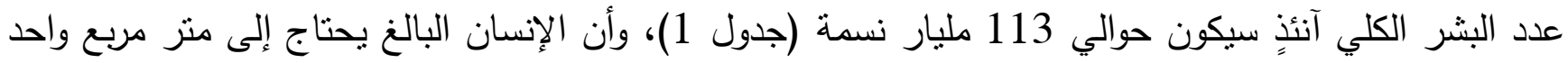
للوقوف، فإن المساحة اللازمة لوقوف جميع البشر وقتنئذ ستكون حوالي 113 مليار منر مربع، محسوبة طبقاً للمعادلة أعلاه (بضرب عدد السكان الكلي بمتوسط المساحة التي يشغلها الفرد الواحد):

\section{3,000,000,000 = 1 x113,000,000,000 (مئة وثلاثة عشر مليار متر مربع)}

وبتحويل هذه القيمة من منز مربع إلى كيلو منز مربع "كم²" (واحد كيلو متز مربع يعادل مليون متر مربع، لذا

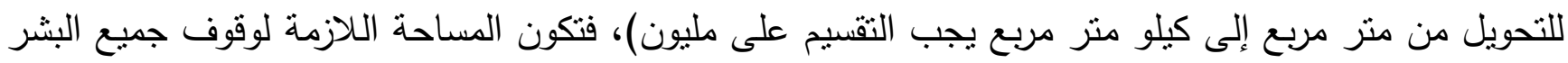

113,000,000,000 — 113,000 1,000,000 (مئة وثلاثة عشر ألف كيلو متر مريع)

بمعنى آخر ، إذا بلغ عدد سكان الأرض الكلي ما يقارب 113 مليار نسمة عام 2050، وأن الإنسان البالغ يحتاج إلى متر مربع واحد للوقوف راجِلاً، فإن مساحة 113 ألف كيلو متر مربع فقط تكفي لوقوف جميع البشر في نفس البس المكان واللحظة. وهذه تُمتّل أكثر بقليل من مساحة بلغاريا، التي تبلغ حوالي 111 ألف كم 2"أو ما يعادل تقريباً 80

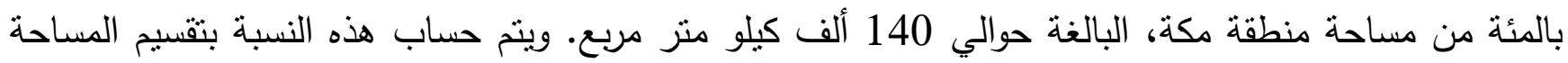
المستتتجة أعلاه (113 ألف كم²) على مساحة منطقة مكة (140 ألف كم²) ثم ضرب الناتج بمئة:

$\% 80.71=100 \times(140,000 / 113,000)$

أما المساحة اللازمة لوقوف جميع البشر بعددهم الحالي (108 مليار نسمة)، فهي 108 ألف كيلو متر مربع، على مبدأ أن الإنسان يحتاج إلى متر مربع واحد للوقوف، وهي أقل بقليل من مساحة كوبا (البالغة 109 ألف كيلو متر

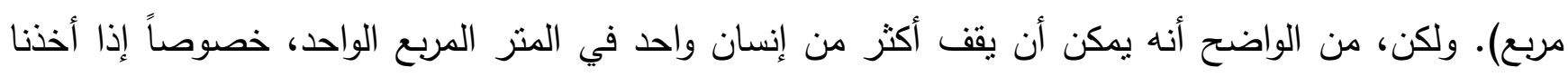

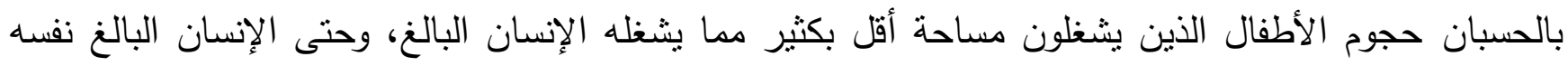

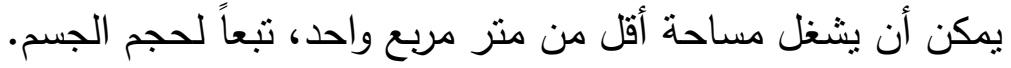

فإذا وقف شخصان اثثان في المتر المربع الواحد، فإن المساحة اللازمة لوقوف جميع البشر المستتجة أعلاه (113 ألف كيلو منر مربع)، ستتخفض إلى النصف، بتقسيم المساحة المستتجة أعلاه على 2 (56,5 (113000

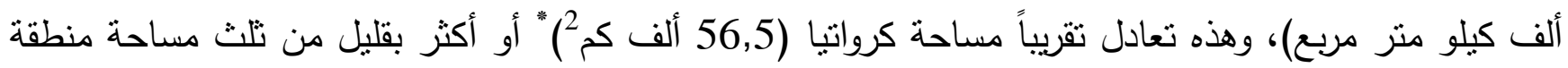
مكة، أو ربع مساحة سوريا (التي تبلغ حوالي 185 ألف كيلو منر مربع)". 


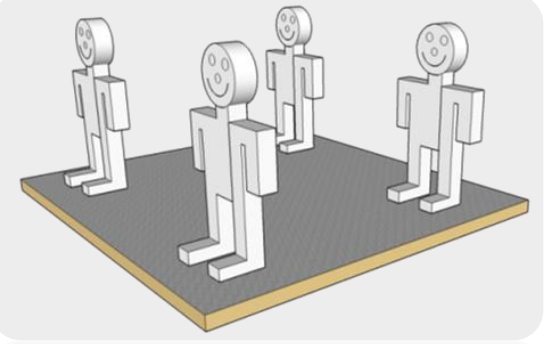

شكل (1). إمكانية وقوف أربعة أثخاص في متر

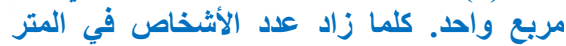

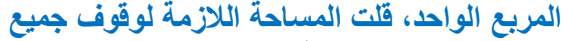
البشر في نفس المساحة، والعكس صحيح.

وإذا ما وقف ثلاثة أنخخاص في المتر المربع الواحد، فإن المساحة السابقة

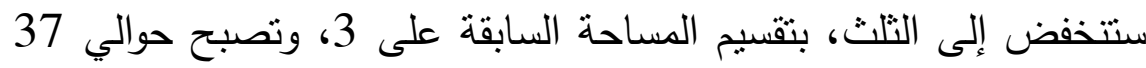
ألف كيلو متراً مربعاً (113000٪ 3=37,7 ألف كيلو متر مربع) وهذه تقارب مساحة نايوان (36 ألف كم²) أو ما يعادل تقريباً ربع مساحة منطقة مكة.

وإذا ما وقف 4 أثنخاص في المتر المربع الواحد (ثنكل 1)، فإن مساحة ما يقارب 28 ألف كيلو متر مربع (113000٪ 4= 28,250) أبي ما يعادل مساحة ألبانيا (28 ألف كم²)" أو 20 بالمئة من مساحة منطقة مكة أو حوالي 15 بالمئة من مساحة سوريا" تكفي لوقوف جميع البشر في نفس المكان. وإذا ما وقف 5 أنثخاص في المنز المربع الواحد، فإن حوالي 22 ألف كيلو منز مربع فقط (113000٪

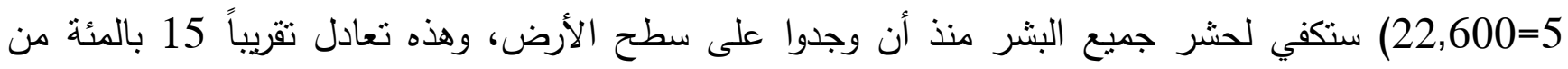
مساحة منطقة مكة المكرمة أو مساحة محافظة دمشق وريفها ودرعا في سوريا (شكل 2) أو أقل بقليل من مساحة جييوتي التي تبلغ حوالي 23 ألف كم². وكلما زادت الكثافة في المتر المربع الواحد قلت المساحة، وبالعكس كلما زادت المساحة اللازمة لوقوف الثخص الواحد ستزداد المساحة الكلية التي تتسع لجميع البشر .

وأخيراً، نتير هذه المُعطيات إلى أن التحذيرات المتكررة من زيادة عدد سكان العالم أو اكتظاظ الأرض بالبشر

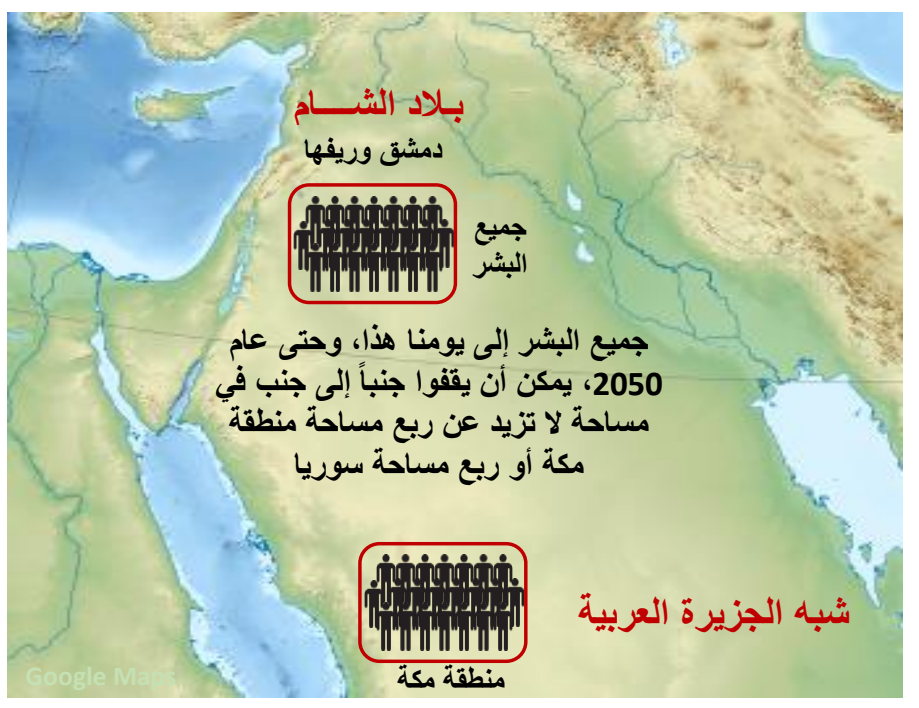

شكل (2). جميع البشر منذ أن وجدوا على سطح الأرض حتى سنة 2050 (أي ما

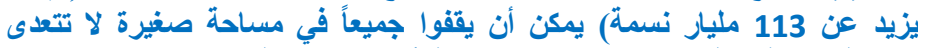

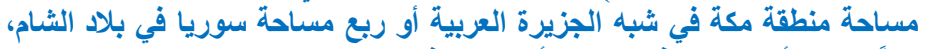

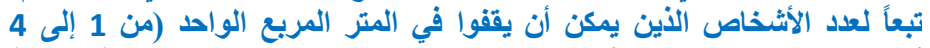

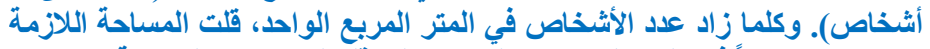
لاستيعابهه جميعاً في نفس المكان، وبالعكس، كلما قل العدد زادت المساحة.
ليست مبررة في جميع جوانبها، خاصة إذا استثينا مشاكل الجفاف والهدر الغذائي والتلوث والازدحام في بعض المناطق، التي يمكن أن نعالج بطرق

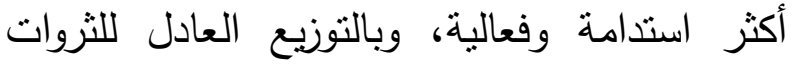
لمحاربة الفقر والإملاق والمجاعة أينما كانت. فالأرض واسعة وغنية، وفيها مسكن ومأكل ومشرب والإنهابه لسكانها لقرون قادمة، إن لم تقم الساعة قبل ذللك،

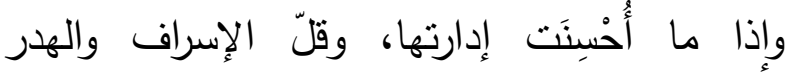
واللامبالاة، وتضامن البشر وتعاضدوا وتعاونوا على لـى الخير والبر، لا على الثر والعدوان والحروب

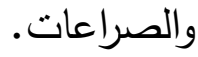




\section{References}

مراجع

* United Nations Statistics Division (UNSD): https://unstats.un.org/unsd/environment/totalarea.htm 